\title{
Conscious approach to urban and extra-urban space restructuring as seen in the designs of Architecture students
}

\author{
Joanna Gil-Mastalerczyk ${ }^{*}$ \\ Ph. D. Arch. Department of Architecture and Town Planning, Faculty of Civil Engineering and \\ Architecture, Kielce University of Technology, 25-314 Kielce, Poland
}

\begin{abstract}
In education of architects and urban planners, it is important to rely on interdisciplinary approach to many factors involved in the process. Especially in the built environment context, the awareness of the interaction of different components is of key importance. In their future work, architecture students need to have responsible and socially-oriented standpoint. It will be demonstrated in the creation of architectural objects in the natural landscape surroundings, and in the attitude to different type of architectural and urban spaces. Safety, the use of natural resources, the relations between architecture and the surrounds, the evaluation of the environmental components and their impact on the creative process are extremely important. The paper discusses examples of space solutions in the urban areas and those located outside cities. Those solutions involve daring architectural and urban forms that make use of the natural environment assets, and also quality architectural work and design. The presence of such objects is a response to the demand from the society, consequently it seems reasonable to explore the issues related to architectural education.
\end{abstract}

\section{Introduction to the Subject Matter}

The paper discusses examples of space solutions in the urban areas and those located outside cities. Those solutions involve daring architectural and urban forms that make use of the natural environment assets, and also quality architectural work and design. The presence of such objects is a response to the demand from the society, consequently it seems reasonable to explore the issues related to architectural education. The latter undoubtedly contributes to the quality of architectural and urban planning projects. The facilities discussed in the paper provide friendly and aesthetic green social space. It offers a large-sized biologically active area that is free from vehicular traffic. Its role is to facilitate social contact by bringing people together. Interaction also means providing residents of different age groups with entertainment. In this context, it is of key importance to design (restructuring) urban fabric in such a way so that the men are at the centre of interest [1], and their specific needs, generally termed behavioural ones, are met [2].

\footnotetext{
* Corresponding author: joanna.gil@onet.pl
} 
The man remembers and identifies space by means of a "spatial code". In this way he creates her "mental maps". K. Lynch proved that users perceive and codify spatial information using five basic elements: paths, districts, nodes and characteristic spatial signs (landmarks) [3, 4]. Public space should be first of all expressive, legible and easily identified so that it can create a useful mental image in the recipient [3].

In the architectural and urban design, it is also important to try to bring timeless value to the architectural objects. That means the objects will address the needs of contemporary and future users, and show respect for the tradition, as innovation is inherently related to tradition.

The subject matter will be presented by referring to the examples of the conceptual designs of architectural and urban objects that have commercial, educational, and recreational functions and are located in the city of Kielce and a small town of Chęciny.

\section{The restructuring to urban and extra-urban space - an important element of the educational process}

At the Kielce University of Technology, Architecture students choose urban and extraurban areas as sites for their daring architectural and urban projects that are intended to serve the needs of local communities. The designs, which draw on the natural environment assets, are meant to combine functionality and uniqueness. Specialized and multithreaded issues related to the reconstruction of urban and suburban spaces have been included in the engineering diploma projects of the first-degree studies at the Faculty of Civil Engineering and Architecture.

The first example concerns architecture that is focused on searching for shapes and natural relations that are characteristic of the project site. In addition to accounting for the features that determine the architectonic and urban form, related, among others to the solar access, the design proposes a conversion of underinvested, wasteland urban area into green functional space. The newly designed area, intended for recreation, is well integrated with the complex of facilities available to users of different age [5]. /The project received the main award in the field of architecture, in the competition for the best diploma thesis in 2017, organized by the Kielce University of Technology and Kielce Technology Park, specializing in the development of new technologies/.

The second design is an attempt at incorporating a new architectural form having exhibition and research function into the site of historical value to the region, and also into body of the forest reserve. The design author's response to the site identity is an original architectural form, to which a sculptural touch was added [6]. /The project received a distinction in the field of architecture, in the competition for the best diploma thesis in 2017, organized by Politechnika Świętokrzyska and Kielecki Park Technologiczny/.

\section{1 "Green Velo Point" - creation of architectural and urban environment with a space for cyclists, city residents and tourists}

The conceptual design involves a large-sized space project, called Municipal Cyclist Service Area in Kielce, i.e. "Green Velo Point". The site includes a section of the Green Velo Eastern Poland Cycling Trail, and it is intended to contribute to the region's identity. The complex of buildings is located in the vicinity of the city centre. It lies adjacent to the Zalew Kielecki water reservoir, between Jesionowa and Zagnańska streets, along one of the major transportation routes in the city. At present, the longest cycle track in the city runs along the Zalew Kielecki water reservoir. The "Green Velo" trail section under design, 2.9 $\mathrm{km}$ in length, is to link the complex of the buildings and the recreational area around the 
reservoir to the very centre of the city and the main street in Kielce, i.e. Sienkiewicza street. The cycle track is compliant with all the requirements posed for the Green Velo cycling trail. The site has an area of 1.7 ha, in which four service buildings are located, namely hotel, restaurant, bike shop with an information point for visitors, and also Cyclist Service Area with sanitary facilities. Recreational part with a large biologically active area that also includes green roofs constitutes a substantial portion of the whole site. Both the cyclists riding along the "Green Velo" trail and the whole city's community can use this space for recreation, walking, contemplation or water sports. The present-day residents of the city hold high expectations about the architectural and urban environment design. Therefore, multi-task design focused on the solutions that meet the needs of users of different age groups, and identified both their potentials and limitations. The guidelines for the concept design and programme addressing the needs of all users were based on the results of the survey. Questionnaires, developed by the students, were returned from over 140 respondents, the users of the cycle track (Fig. 1).

The characteristic feature of the designed city space, which contributes to its identity, is clear spatial arrangement. It should produce positive aesthetic perceptions and a general feeling of safety in all the users. The areas between buildings are designed to be functional and accessible to everybody. Widely understood urban context includes transport infrastructure, technical facilities, green spaces and also recreational and sports areas.

Ascetic use of the means of expression and massive form of the building evoke organic structure that was hollowed out. The urban shape results from the slope of the land, which is seamlessly merged with the architectural form of the buildings. The concept of the building as a sculpture carved from a natural material is inspired by the surrounding natural landscape. Cutting gently into the surrounding terrain, the architectural object situated on the reservoir bank blends with the adjacent area. The object is open to the landscape, but simultaneously forms a clearly distinct space separated from the surrounds. To enhance the object integration into the surroundings, the roof was designed in such a way so that it could be grown with vegetation. All the roofs were incorporated into the reservoir surroundings and made available to all the users. The roof planes slope gradually towards the ground, so everybody can enter each level without any limitations. That provides an interesting example of architecture merging with nature and creating a green space for recreation in the dense fabric of the city. It becomes a green oasis for the city residents, at the same time, however, it is a landscape component with a clearly defined character.

On the side of the reservoir, the complex is surrounded by greenery intended for recreation and sports, which was designed with respect to outstanding natural conditions. The green bank area is dedicated to walkers, joggers and children. "Green beach" was designed for families and playgrounds were cast. In this way, a harmonious transition from nature to the built environment was created.

The space provides a universal modern built environment, which promotes active lifestyle among modern city dwellers. Priority has been given to architectural and urban solutions intended for recreation and contemplation aimed at people of different ages, children, youths and adults. Open integrating forms are predominant, they were consciously chosen to integrate the needs of tourists and residents of different ages. The buildings' architecture became related to the existing land use, as it opens to nature and blends with landscape.

The informed observations indicate that the highest valued parts of the city show explicit spatial order, openness, tidiness and abundance of greenery that allows physiological relaxation [7]. Green architecture contained in the design makes use of the latest solutions, and offers comfort of use. At the same time, designs of that type require constant broadening of architect's knowledge and a possibility of its application. 
As for courses in architecture offered to students, it is important that the designs they develop should be kept up to date with the current trends in architectural design. City dwellers expect the designers will provide them with generally better standards as regards recreation (...) [8] [9].

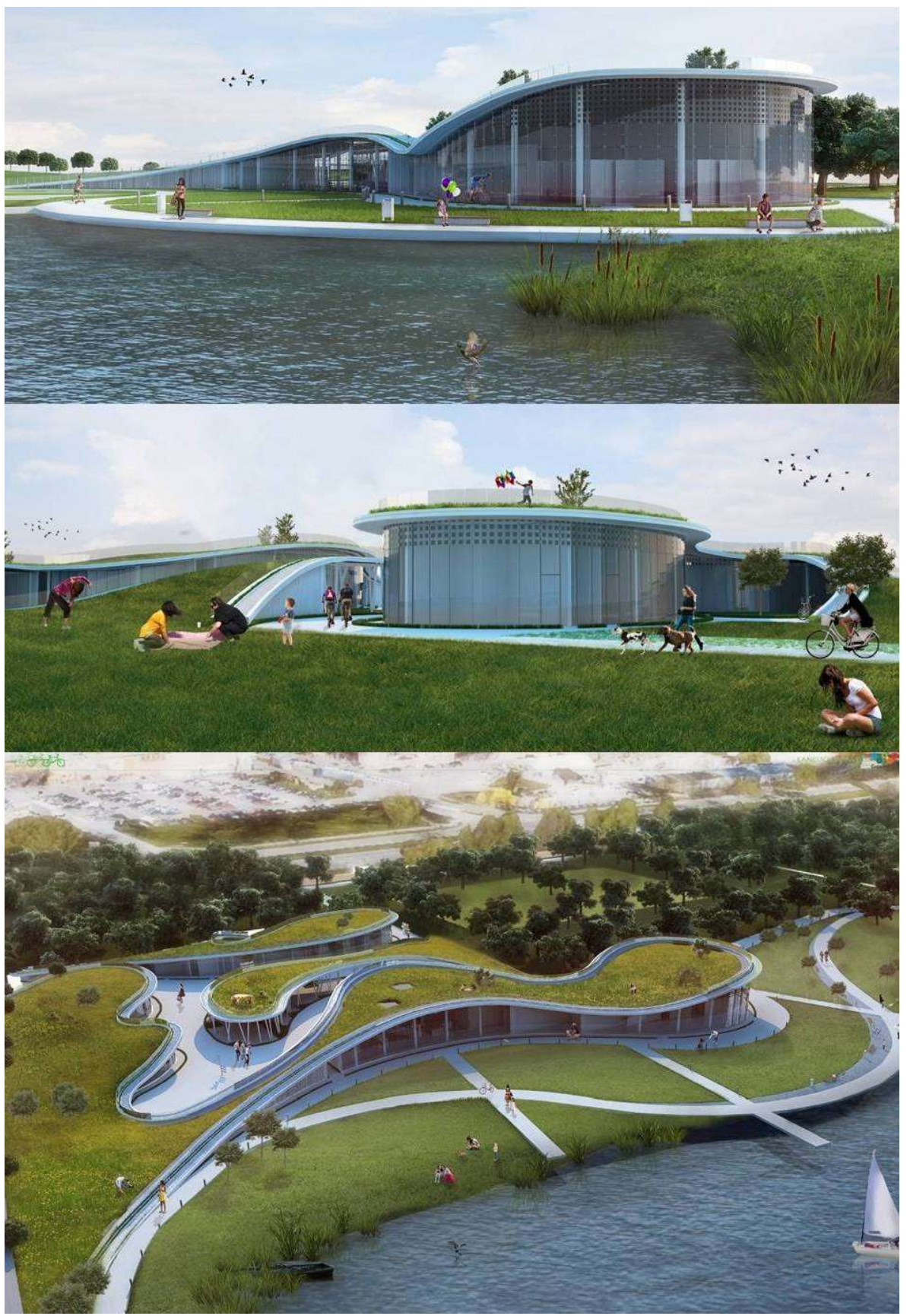

Fig. 1. "Green Velo", Kielce, Poland. Source: [5]. 


\section{2 "Jaskinia Raj" (the Paradise Cave) - creation of architecture set in the natural forest landscape. Space dedicated to culture, research and recreation}

The other diploma design concerned exhibition and research centre located at the Jaskinia Raj (in Polish - Paradise Cave) near Chęciny. The centre is situated in the precious nature area within the "Jaskinia Raj" natural reserve, which lies approx. $10 \mathrm{~km}$ from the centre of Kielce. The object was designed with the intention of popularising knowledge of geology and archaeology and building interests in those fields in different age groups. Due to great historical and landscape value of this site, the design project focused on the refurbishment of the existing infrastructure and the restoration of the complex. The works covered the entrance pavilion, the temporary building of the first centre of the Neanderthal Man and the immediate surrounds. According to the design author: the principal design strategy was to incorporate a newly designed object into the existing natural fabric, so that the whole project would make a harmonious entity. The architectural form, together with the landscaping of the surrounds, would enhance the natural features of the locality, and also integrate with the forest environment [6].

Jaskinia Raj is located at the heart of the forest, in the slope of the hill called Malik. The latter lies in the Bolechowickie range of the Chęcińskie Hills, which form the south eastern part of the Świętokrzyskie Mountains. The site is particularly suited to those interested in active recreational activities. Obviously, it also provides contact with nature. Walking trails are available for tourists in the area.

The design produced a harmonious composition, highly valued for its aesthetics and allowing only minimal intrusion to the existing natural landscape. The form of the object and landscaping of the surrounding area emphasise the greatest assets of the site and show respect for the natural scenery (Fig. 2, 3).

The building location became a major factor when the design was developed. An architectural form was introduced into the natural wooded landscape, yet the form does not dominate the site. Instead, the form complements the natural area creating a joint composition. [6]. The subdued colour palette and greenery covering the roof planes contribute to the total integration of the architectural form with the existing forest landscape. The building shape provides only a backdrop to the beauty of surrounding nature. That is why the remaining part of the whole facility was left intact. The cave is accessed via a path running through the woodland. Thus, all the visitors to the cave are exposed to nature that is inherently related to the architecture and function of the centre.

The object originated from the idea that the existing entrance pavilion should be substituted with a new building compliant with current technological, functional and aesthetic principles. At present, Jaskinia Raj is a major tourist attraction in the region, but apart from a visit to the cave interior, it does not offer other activities. People leave the cave stunned with its beauty and uniqueness, but they still feel that somehow, they could go for more [6].

In the newly designed space, it is possible to explore issues concerning geology, archaeology and palaeontology. A new site was created, where there are still many things to see after you have visited the cave.

In the design of the Exhibition and Research Centre, a special attention was paid to the surrounding space. The views from the building were focused on the natural landscape, which was achieved by means of the building form.

The attractive arrangement of geometric forms enhances the character of the building and sets the mood of the interior. The use of concrete and glass in the facades is another factor that integrates the form and the landscape, and affects the general perception. Transparent external glazing in the form of large glass panels allow large amount of natural light to access the interior, and also opens the structure onto nature. The facades directly communicate with the surrounds. The façade construction ensures the close presence of 
nature, whereas glazing allows spectacular views of the forest greenery. All the components, namely glazed facades and green roof help integrate human environment with nature, and also improve microclimatic conditions [10].

The functional structure and the exhibition and research offer with the floor area of $2091.03 \mathrm{~m}^{2}$,are complemented by a catering area with a café, and the recreational one with a viewing platform, and also sloping green roofs that are accessible to all visitors and act as an extension to landscape. The roof perfectly blends with the adjacent nature creating a joint composition. The architectural shape seems to continue into a rock mountainous formation emerging from the densely wooded space.

All the materials used in construction correspond to the geology and vegetation of the site. The object cover, with a clear-cut form, was designed as an intensive green roof. The application of that type of solution allowed further merging of the structure with nature and giving it eco-friendly character [6].

Light spacious interiors make it possible to watch the landscape outside. The visitors can enjoy exhibition space and explore research space. Thus, the object becomes an integral part of the exhibition programme. The austere style of the interior is characterized by emphasis on architectural concrete as internal wall lining. That produced a coherent perception of the whole object. The use of timeless monolithic look complements the value of the exhibits, which could be modified in the future without altering the spirit of the object. The room height can accommodate various configurations of exhibits. The full-size replica of the mammoth skeleton will definitely fit inside. Minimalist interior finishing, together with glazing, provides an ideal background to the natural surroundings.

It should be noted that the architectural concept was adjusted to the natural terrain topography. It contributes to the existing environment. The scale and form of the object perfectly fit into the surrounds. The dynamic shape of the object can become a prominent landmark of the region. The space designed creates a unity of architecture and landscape, and also of the present and the past.

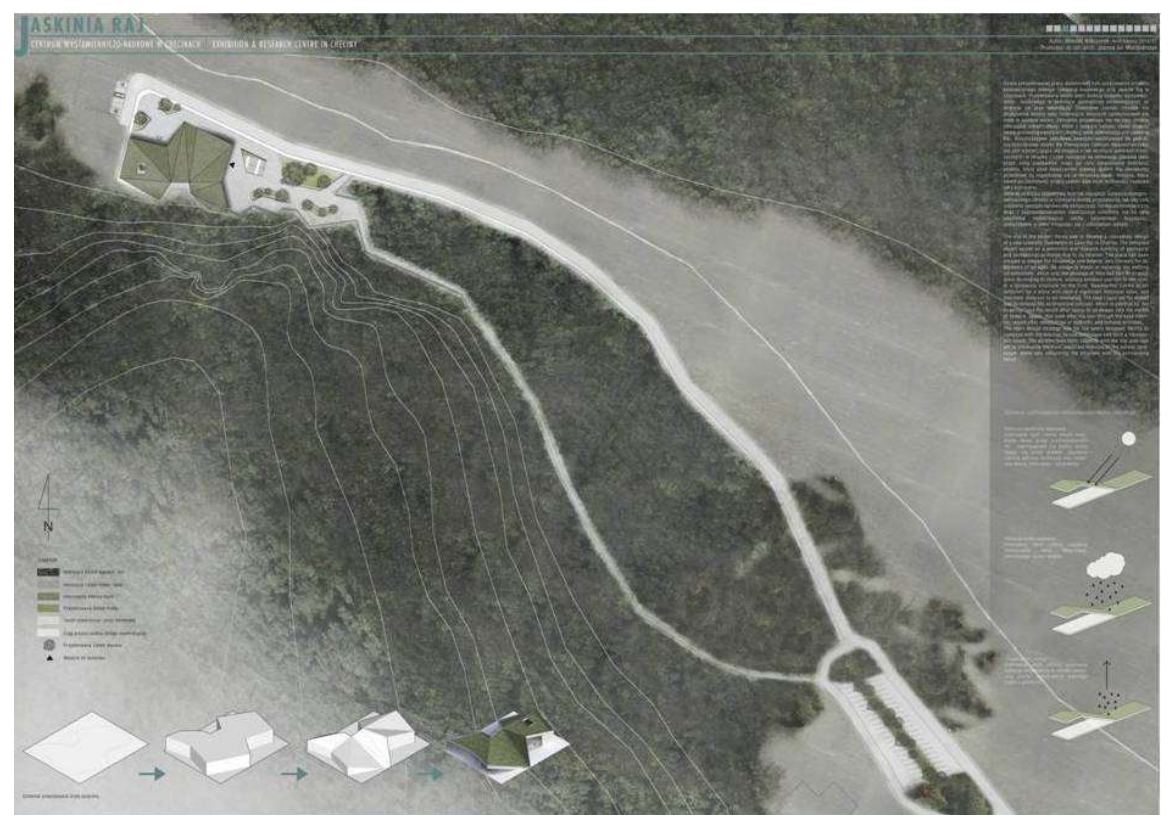

Fig. 2. "Jaskinia Raj" (the Paradise Cave), Chęciny, Poland. Situation Plan. Source: [6]. 

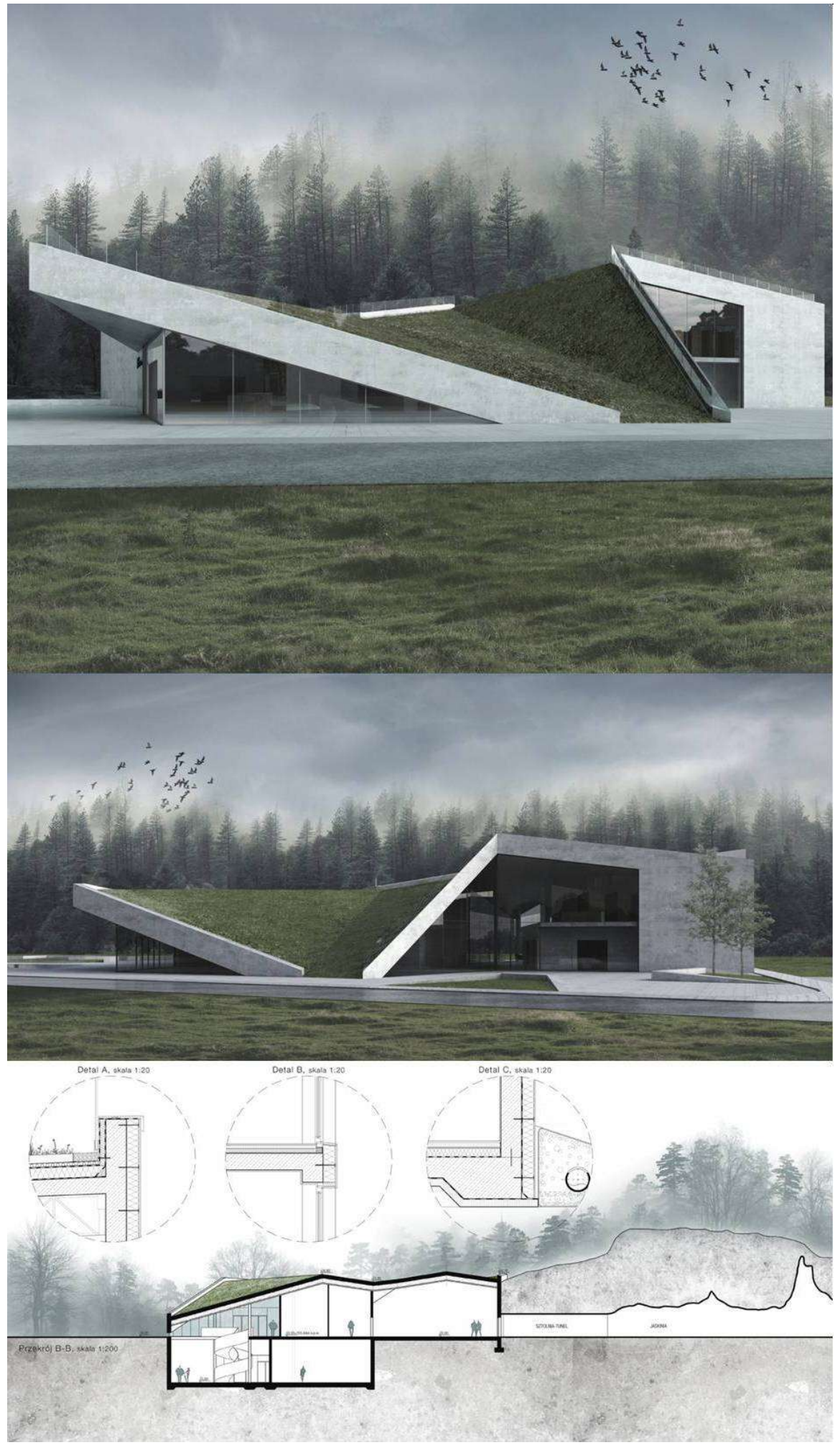

Fig. 3. "Jaskinia Raj" (the Paradise Cave), Chęciny, Poland. Source: [6]. 


\section{Summary and conclusions}

The students' designs discussed in the paper are based on modern architectural practices. The designs facilitate the promotion and popularisation of the region. They also help emphasise the unique assets of the region's natural environment. The principal strategy behind the concepts presented in the paper is the total integration of the building form with the surrounding landscape. The decisions taken during the design process were based on the results of investigations into the pre-existing natural context. The forms and scale of the objects were adjusted to the terrain topography and landscape features. The objects harmoniously merge with the surrounding areas and enhance the value of the existing environment. Minimalist use of materials helped subtle blending of the facilities with the landscape.

To sum up, it should be noted that architectural and urban concepts developed by the authors are in close contact with nature. The designs undoubtedly contributed to increased awareness of the relations between humans and the environment. In education of architects and urban planners, it is important to rely on interdisciplinary approach to many factors involved in the process. Especially in the built environment context, the awareness of the interaction of different components is of key importance. In their future work, architecture students need to have responsible and socially-oriented standpoint. It will be demonstrated in the creation of architectural objects in the natural landscape surroundings, and in the attitude to different types of architectural and urban spaces - in the urban areas and those located outside cities. Safety, the use of natural resources, the relations between architecture and the surrounds, the evaluation of the environmental components and their impact on the creative process are extremely important.

\section{References}

1. J. Gehl, Cities for people, Island Press, (2010)

2. E. Niezabitowska, Architektura a środowisko zbudowane, [in:] Środowisko zbudowane w stużbie człowieka. Człowiek-potrzeby-środowisko, Katowice, (2005)

3. K. Lynch, The Image of the City, Massachusetts Institute of Technology, 9 (1960)

4. E.C. Tolman, Cognitive Maps in Rats and Man. Psychological Review, 55, 4 (1948)

5. M. Kałuża, "Green Velo Point" as a place of regional identification. (Diploma Project, Promoter: Ph. D. Arch. J. Gil-Mastalerczyk, Kielce University of Technology, Faculty of Civil Engineering and Architecture) Poland, Kielce, (2017).

6. M. Wieczorek, "Jaskinia Raj"- EXHIBITION and Research Centre in Chęciny. (Diploma Project, Promoter: Ph. D. Arch. J. Gil-Mastalerczyk, Kielce University of Technology, Faculty of Civil Engineering and Architecture) Poland, Kielce, (2017).

7. M. Lewicka, A. Bańka, Psychologia środowiskowa [in:] Psychologia t. II. Akademic Book - J. Strelau. Gdańskie Wydawnictwo Psychologiczne, Gdańsk, (2008)

8. K. Ujma-Wąsowicz, M. Bielak, Urban Aspects of Built Environment Development for 50+Age Group Users, [in:] Technical Transactions, Architecture, Cracow University of Technology, 1-A/2/2012, Issue 1, Year 109, Krakow, 269-276, (2012)

9. M. Carmona, i inni, Public Places, Urban Spaces. The Dimensions of Urban Design, Architectural Press, 285 (2008)

10. L. Kamionka, Glazed Elevation and Green Roof as Important Elements of Modern City Integrationenvironment of Person's Life and Nature [in:] The Modern City as a Human Environment Integrated With Nature, (Ed.) S. Wehle-Strzelecka, 2/2015, Kielce University of Technology, Kielce, 146-152 (2015) 